Cipango $\begin{aligned} & \text { Cipango } \\ & \text { Cahiers d'études japonaises }\end{aligned}$

15 | 2008

Guerre, colonialisme et commémoration

\title{
Quelques aspects de la culture populaire d'Okinawa
}

Some Aspects of Okinawan Popular Culture

\section{Masanobu Akamine}

Traducteur : Patrick Beillevaire

\section{CpenEdition}

\section{Journals}

Édition électronique

URL : https://journals.openedition.org/cipango/407

DOI : $10.4000 /$ cipango.407

ISSN : 2260-7706

Éditeur

INALCO

Édition imprimée

Date de publication : 1 janvier 2008

Pagination : 207-228

ISBN : 978-2-85831-177-4

ISSN : 1164-5857

\section{Référence électronique}

Masanobu Akamine, "Quelques aspects de la culture populaire d'Okinawa », Cipango [En ligne], 15

2008, mis en ligne le 13 novembre 2011, consulté le 30 juin 2021. URL : http://

journals.openedition.org/cipango/407 ; DOI : https://doi.org/10.4000/cipango.407

Ce document a été généré automatiquement le 30 juin 2021.

\section{(c) (1) \&}

Cipango est mis à disposition selon les termes de la Licence Creative Commons Attribution - Pas d'Utilisation Commerciale 4.0 International. 


\title{
Quelques aspects de la culture populaire d'okinawa
}

\author{
Some Aspects of Okinawan Popular Culture
}

\author{
Masanobu Akamine \\ Traduction : Patrick Beillevaire
}

\section{Avant-propos, par Patrick Beillevaire}

1 À en juger par le nombre des publications universitaires qui lui sont consacrées, le département d'Okinawa, aujourd'hui 1370000 habitants, est certainement l'une des régions du monde les plus intensément étudiées. Par sa culture, comme par sa place singulière dans l'histoire de l'Asie orientale, ce département périphérique, né de l'annexion du royaume des Ryūkyū au cours des années 1870 - période dite du Ryūkyū shobun 琉球処分, ou de «mise en ordre» de cette région autonome au statut international incertain -, forme un ensemble distinct de la métropole japonaise, lui-même intérieurement très différencié. Ainsi qu'en témoigne l'étude publiée à Tōkyō dès 1914 par le chercheur allemand Edmund Simon, «Riukiu, ein Spiegel für Alt-Japan » (Ryūkyū, miroir du vieux Japon), les historiens comme les ethnologues ou folkloristes de la première moitié du siècle dernier ont généralement appréhendé la culture et l'histoire de ces îles à l'aune de celles de la métropole, dans l'espoir, notamment, d'y découvrir les vestiges d'un Japon encore non imprégné par le bouddhisme. Une telle disposition d'esprit se retrouve aussi bien dans les travaux du philologue et historien natif d'Okinawa Iha Fuȳ 伊波普猷, familièrement désigné comme le "père des études sur Okinawa» (Okinawa-gaku no chichi 沖縄学の父), que dans ceux de Yanagita Kunio 柳田国男, d'Orikuchi Shinobu 折口信夫 et de leurs compagnons, originaires d'Okinawa ou de la métropole.

2 S'il est vrai que la doctrine bouddhique, en tant que telle, n'a que superficiellement pénétré les îles Ryūkyū jusqu'à une époque récente, c'était là méconnaître l'influence qu'eurent les courants de pensée présents sur le continent et au Japon dans la transformation des croyances locales, sans doute dès le XII siècle, qui aboutit à l'élaboration d'une idéologie royale et d'un système étatique très originaux. Il faut attendre les années 1960 et 1970 pour que cet apport extérieur commence à être déchiffré dans toute son ampleur. Surtout, contrairement au souhait exprimé 
par Iha Fuȳu de voir la culture ryūkyū reconnue comme une composante de plein droit de la culture nationale, la démarche antiquisante tendait à justifier la subordination politique et culturelle d'okinawa à une métropole, vecteur obligé et accepté de la civilisation moderne. Ce préjugé intellectuel alla souvent de pair, comme on sait, avec une discrimination à la fois raciale et morale, en dépit du credo officiel de l'origine commune des Japonais et des habitants des Ryūkyū (Nichi-Ryū dōso-ron 日琉同祖論) et de l'égalité législative et juridique conférée très tôt à ces derniers.

3 La bataille qui dévasta l'île d'okinawa au printemps de 1945 et les vingt-sept années d'occupation américaine qui s'ensuivirent ont causé une profonde rupture dans le cours de l'histoire d'okinawa, même s'il faut garder à l'esprit que sa population a ensuite exprimé massivement son attachement à la nation japonaise en prenant derechef argument de la parenté ethnique. Dans le champ de ce qui reste souvent appelé "études folkloriques", de nouvelles générations de chercheurs familiers des théories et méthodes de l'anthropologie européenne ou américaine, dans le sillage d'un Mabuchi Tōichi 馬淵東一 formé sur les terrains coloniaux et bon connaisseur des travaux de l'école de Leiden, ont contribué à mettre en valeur tout ce qui distingue Okinawa de la métropole. Certains de ces éléments différenciatifs paraissent issus d'un fonds primitif immémorial, d'autres sont clairement empruntés aux sociétés du continent avec lesquelles les habitants des Ryūkyū ont été en contact, de la péninsule coréenne à l'Insulinde. Bien que la discontinuité avec la période d'avant la guerre soit moins marquée dans le champ de la recherche historique, celle-ci, par une évolution comparable, a révélé, entre autres choses, l'importance des relations commerciales que le royaume des Ryūkyū, à présent communément promu "carrefour de l'Asie orientale ", a entretenues avec ses voisins asiatiques, en même temps que la complexité d'un appareil étatique dont, entre autres traits, l'autorité administrative couvrait aussi le domaine religieux, de la cour royale au village. Ainsi, s'est effacée l'idée d'une histoire qui n'aurait été qu'un surgeon de celle du Japon, de surcroît atrophié par la mainmise jalouse qu'exerça sur ces îles le fief de Satsuma à partir du XVII siècle. L'aspiration à l'autonomie, voire à l'indépendance, peut bien n'être aujourd'hui que marginale, comme en atteste continûment le choix des électeurs, les habitants d'Okinawa se sont désormais réappropriés leur histoire pour y puiser, volontiers oublieux des assujettissements, les emblèmes d'une singularité qu'ils souhaitent être un atout du développement économique de leur région.

4 Le texte ici présenté reste apparemment neutre à l'égard de la question des liens entre la métropole japonaise et Okinawa. Sans doute parce qu'ils mettent en évidence plus de diversité que d'unité et que leur registre demeure celui de la tradition et du microcosme villageois, les travaux des anthropologues ou des folkloristes n'ont ordinairement pas d'écho direct dans le discours politique. C'est plus naturellement dans l'expérience historique que celui-ci trouvera à l'occasion des arguments, lorsque, comme le fit le gouverneur Ōta Masahide 大田昌秀 (1990-1998), est rappelé le coup de force qui décida de l'annexion des îles Ryūkyū ou l'enchaînement entre les pratiques discriminatoires d'avant la guerre et l'actuelle concentration des forces américaines sur l'île d'Okinawa. Au premier abord, l'exposé d'Akamine Masanobu n'a d'autre ambition que de présenter les aspects généralement considérés comme les plus caractéristiques d'une culture traditionnelle qui a subsisté, peu ou prou, jusqu'au milieu du $\mathrm{xx}^{e}$ siècle, sinon jusqu'à aujourd'hui. Néanmoins, on relèvera qu'en soulignant à la fois l'origine assez récente de certaines pratiques et les effets de diffusion à partir d'une culture aristocratique soumise aux influences extérieures, la notion même d'une identité pérenne, dont se nourrissent habituellement les projets sécessionnistes, se trouve ici directement mise en question. 


\section{Quelques aspects de la culture populaire d'Okinawa}

5 Aujourd'hui département du Japon, Okinawa a connu une histoire singulière qui ne ressemble à celle d'aucune autre région de ce pays. Les îles qui composent ce département ont en effet constitué autrefois un royaume indépendant appelé Pays de Ryūkyū (ch. Liúqiú-guó ; jap. Ryūkyū- koku 琉球国) ${ }^{1}$, nom donné à l'archipel par les Chinois. Cet État, déjà tributaire officiel de l'Empire chinois au moment de sa formation, au début du $\mathrm{Xv}^{\mathrm{e}}$ siècle, connaît d'abord deux siècles de grande prospérité grâce à son commerce avec la Chine, le Japon, la Corée et les pays ou cités portuaires du Sud-Est asiatique. En 1609, l'île d'Okinawa est envahie par les soldats du han de Satsuma 薩摩藩, situé au sud de Kyūshū. Le royaume passe alors sous la domination des Shimazu 島津, les seigneurs de ce fief, et par leur entremise doit également payer tribut au gouvernement d'Edo². Son existence, en tant qu'État distinct, se poursuit néanmoins jusque dans la seconde moitié du XIX ${ }^{e}$ siècle. Finalement, en 1879 , son territoire est incorporé à l'Empire japonais sous le nom de département d'Okinawa. Dans la dernière phase de la Seconde Guerre mondiale, l'affrontement des armées japonaise et américaine cause la mort d'environ un quart de ses habitants. Après la guerre, l'archipel reste administré par les États-Unis, et ce n'est qu'en 1972 qu'il est restitué au Japon et redevient le département d'Okinawa.

6 Telle est, très succinctement résumée, l'histoire de ce département. Voyons maintenant ce qu'il en est des relations entre la culture populaire d'Okinawa et celle du Japon. La question est en réalité fort complexe tant il existe à la fois de similitudes et de différences entre elles. Pour les linguistes, le japonais et la langue ryūkyū, dont les dialectes parlés sur l'île d'Okinawa sont une des composantes, sont des langues sœurs possédant une origine commune. Toutefois, malgré cette proximité, l'intercompréhension est impossible entre les locuteurs des deux langues. On estime que la distance entre la langue (ou dialecte) d'Okinawa et le japonais est plus grande que celle qui sépare l'espagnol $\mathrm{du}$ portugais, langues entre lesquelles l'intercompréhension serait d'environ 50 pour cent. Plus globalement, on peut dire d'emblée que, bien que se rattachant à l'ensemble culturel japonais, la culture d'Okinawa présente de profondes originalités par rapport aux autres variantes régionales de cet ensemble. L'examen de quelques aspects importants de celle-ci montrera ce qui l'en distingue principalement.

\section{Le pouvoir spirituel des femmes}

7 La prééminence des femmes dans le domaine religieux est sans doute la caractéristique la plus notable de la culture d'Okinawa. Nous allons aborder cette question sous l'angle de la «croyance dans l'unai-gami» (unai-gami shinkō ウナイ神信仰), onari-gami en japonais standard, littéralement la « divinité sororale ». Unai est le terme qu'emploie un homme pour désigner ses sœurs. À l'inverse, une femme désigne ses frères par le terme wiki. C'est là un système terminologique sexuellement différencié qui distingue la langue ryūkyū du japonais.

8 Ce qui fonde la croyance dans l'unai-gami, c'est le " pouvoir de protection spirituelle » (reiteki ni shugo suru chikara 霊的に守護する力) que les sœurs, unai, sont censées posséder à l'égard de leurs frères. Un ancien chant (ryūka 琉歌) très connu, intitulé «L'oiseau blanc» (Shiratuyā bushi 白鳥節) ${ }^{3}$, dit ainsi : 
御船の高艣に[船ノ高艫二]

白鳥が居いちょん[白イ鳥ガ止マッテイル]

白鳥やあらん[白イ鳥デハナイ]

うみないおすじ [姉妹ノ生御魂夕゙ ${ }^{4}$

9 Le sens de cette phrase est le suivant: alors que le bateau file sur la mer, un oiseau blanc se pose sur sa proue; mais ce n'est pas un oiseau ordinaire, c'est l'esprit de la sœur de l'homme embarqué sur le bateau qui s'est incarné dans un oiseau blanc pour le protéger. Le chant se poursuit :

うみないが手巾 [姉妹ノ手拭八]

まぼるかんだいもの[我ガ守護神ナレバ]

引きまわち給机 [我集庇護シ給へ]

大和までいん [日本ニ行ツテマデモ] $]^{5}$

En donnant un morceau d'étoffe (tīsāji) à son frère, la sœur lui a accordé sa protection personnelle, et elle veille sur lui durant son voyage jusqu'au Yamato (désignation la plus courante du Japon à Okinawa). Il est ici fait référence à la coutume très ancienne selon laquelle, lorsqu'un homme part en voyage, sa sœur lui offre comme " amulette " (o-mamori お守り) un morceau d'étoffe qu'elle a elle-même tissée. Cela peut aussi être une mèche de cheveux, comme on l'observa souvent, durant la dernière guerre, quand les hommes étaient envoyés combattre sur le front.

11 Dans certaines régions d'okinawa, la croyance dans l'unai-gami se manifeste également par le fait que c'est la sœur du maître de maison, partie vivre dans une autre maison après son mariage, qui conduit les rites liés au cycle agricole dans sa maison natale, devenue la maison de son frère aîné, et non l'épouse de ce dernier.

12 Voici une histoire réelle qui met en relief la conception de la structure familiale sousjacente à cette croyance. Une femme d'Okinawa, récemment mariée avec un homme de Hondo et vivant à Ōsaka, revenait pour la première fois, seule, visiter sa maison natale à Naha. À cette occasion, sa belle-mère d'Ōsaka téléphona chez ses parents en leur disant : uchi no yome ga o sewa ni narimasu node... ウチの嫁がお世話になりますので... , « je vous remercie de prendre soin de "notre belle-fille" (uchi no yome, littéralement, "la jeune mariée de chez nous") ». Ces derniers, surpris, ne comprirent pas tout de suite ce qu'elle voulait dire. À Okinawa, il est courant qu'une femme mariée rende quotidiennement visite à sa maison natale et qu'elle continue de s'y sentir chez elle. Au contraire, du point de vue de cette belle-mère d'Ōsaka, la femme qui avait épousé son fils était devenue une "femme de sa propre maison », uchi no yome, et il lui paraissait donc normal d'exprimer de la reconnaissance pour l'accueil fait à sa belle-fille, même dans la maison natale de celle-ci. L'écart entre la culture japonaise et la culture d'Okinawa qu'illustre cette histoire me semble se rattacher en partie à la croyance dans l'unai-gami.

13 Dans son principe, cette croyance a en effet pour corollaire la force des liens entre les femmes et leur maison natale (jikka 実家, la maison paternelle). Pour une femme mariée, la maison de son frère, auquel elle doit protection, reste aussi la sienne ${ }^{6}$. Au demeurant, si l'usage est maintenant d'enterrer les femmes au côté de leur mari dans la tombe appartenant à la famille de ce dernier, dans le passé, comme le montrent les archives familiales, leur dépouille rejoignait bien souvent la tombe de leur maison natale ${ }^{7}$.

14 Qu'en est-il donc, ici, de la relation entre mari et femme? Si la croyance dans le 《 pouvoir spirituel inné » (reiteki na shishitsu 霊的な資質, reiteki na chikara 霊的な力) 
des femmes, très supérieur à celui des hommes, est un trait fondamental de la culture d'Okinawa - ce que résume la notion d'unai-gami-, il est toutefois admis que ce pouvoir ne s'exerce qu'à l'avantage des frères, et non des maris. Une légende raconte ainsi qu'un homme pris dans une tempête reçut l'aide de sa sœur métamorphosée en oiseau blanc, tandis que son épouse, sous l'apparence d'un oiseau noir, s'efforçait, elle, de faire sombrer son navire. On rapporte aussi, dans une certaine île, qu'un homme fut vivement critiqué par les gens de son village pour avoir été secouru par son épouse, et non par sa sœur, alors qu'il était en danger sur la mer. Mais pourquoi une telle réprobation? La raison avancée était que, si cet homme avait disparu en mer, l'épouse aurait eu la possibilité de se remarier, alors que pour sa sœur il était à jamais irremplaçable. Le mariage étant une sorte de relation contractuelle, ce raisonnement n'est pas sans logique. Pourtant, on peut entrevoir, là aussi, l'idée, liée à la croyance dans l'unai-gami, que la relation entre un frère et une sœur est à la fois première et plus forte que celle entre un mari et sa femme. Mais peut-on expliquer qu'une société accorde moins de valeur à la relation entre des époux qu'à celle entre un frère et une sœur?

15 La primauté de la relation frère sœur sur le lien matrimonial dans la culture d'Okinawa fait bien sûr songer à l'organisation familiale des sociétés matrilinéaires. En Inde, par exemple, la caste des Nayar forme une société matrilinéaire dans laquelle l'unité d'habitation est composée des frères et des sœurs, ainsi que des enfants de ces dernières. Les maris, qui résident en permanence dans une autre maison, ne font que rendre visite à leurs épouses. Sans doute cette faiblesse structurale de la relation matrimoniale est-elle une caractéristique générale des systèmes matrilinéaires. Cependant, bien que la croyance dans l'unai-gami puisse justifier de rapprocher la culture d'okinawa de celles des sociétés matrilinéaires, rien ne prouve qu'une société de ce type y ait jamais existé ${ }^{8}$. Cela ne nous permet donc pas de trouver là un fondement sociologique à l'importance particulière que cette culture accorde à la relation frère sœur.

\section{Le système des prêtresses}

16 Un des traits les plus originaux de l'ancien royaume des Ryūkyū est son système de prêtresses responsables de la conduite des cérémonies religieuses, du sommet de l'État au niveau villageois (shinjo soshiki 神女組織). Celui-ci était distinct du «système administratif» (gyōsei soshiki 行政組織), apanage des hommes, à la tête duquel se trouvait le roi. Les prêtresses étaient organisées hiérarchiquement, avec la kikoe-ōgimi 聞得大君 au plus haut échelon et les noro qui officiaient dans les villages. Bien qu'elle ait pu être ensuite attribuée à l'épouse ou à la mère du roi, la charge de kikoe-ōgimi incombait en règle à une sœur du roi à l'époque la plus ancienne du royaume. On ne peut manquer de voir là une autre manifestation du «principe de l'unai-gami » (unaigami no genri ウナイ神の原理) précédemment évoqué 9 . Toutes les prêtresses rassemblées autour de la kikoe-ōgimi étaient en particulier responsables des rites pour la paix et la prospérité du pays célébrés, entre autres lieux, dans les utaki 御嶽 du " palais royal » (ōkyū 王宮), autrement dit du « château de Shuri » (Shuri-jō 首里城). Je parlerai un peu plus loin de ces utaki qui sont des espaces sacrés comparables aux sanctuaires shintō du Japon. 
Les noro étaient nommées par une « ordonnance » royale (jireisho 辞令書) ${ }^{10}$. Avec leur charge, une parcelle de terre leur était attribuée, suffisante pour assurer leur subsistance. Leur statut, pour emprunter le vocabulaire d'aujourd'hui, était celui de fonctionnaires régionaux. Entourées d'officiantes locales, elles avaient pour tâches ordinaires de diriger les cérémonies villageoises organisées dans les utaki ou ailleurs pour l'obtention de récoltes abondantes. Il existe également des fonctions rituelles masculines à Okinawa, mais celles-ci sont normalement d'ordre subalterne. Avec le démembrement du royaume, à la fin du XIX ${ }^{e}$ siècle, la fonction de noro a perdu son caractère officiel. Elle a cependant persisté jusqu'à aujourd'hui dans les villages, bien qu'elle soit maintenant en voie de disparition.

18 En dehors des noro et des autres prêtresses villageoises qui leur sont associées, il existe à Okinawa des sortes de shamans, appelés yuta, dont le rôle est également très important dans la religion populaire. La grande majorité de ces yuta sont des femmes, sans doute à plus de 90 pour cent, bien que les statistiques soient sur ce point imprécises. Elles diffèrent des noro, et autres prêtresses de ce type, en ce qu'elles n'interviennent généralement pas dans les rites communautaires, mais, répondant à des demandes individuelles, se consacrent à la recherche des causes surnaturelles d'un malheur ou d'une maladie et à l'interprétation des augures. Elles peuvent aussi recevoir des messages des morts et les transmettre aux personnes concernées. À la différence des noro, dont les fonctions furent institutionnalisées par le pouvoir royal, les yuta, qualifié(e)s de «malfaiteurs [yakara 輩] trompant le peuple par des mensonges », furent souvent réprimées par les autorités. Même à l'époque moderne, leurs activités ont continué à faire l'objet d'une étroite surveillance par la police. Malgré cela, de nos jours encore, leur influence est loin d'être négligeable ${ }^{11}$.

\section{Les concepts du divin}

19 L'un des mots-clefs pour comprendre la religion d'Okinawa est celui d'utaki 御啍. Un utaki se présente typiquement comme une petite clairière dans un bosquet très dense. Chaque village en possède au moins un, où sont accomplis la plupart des rites communautaires. Mais il existe également des utaki, ou des espaces sacrés assimilables à ceux-ci, dans les anciennes «résidences seigneuriales» (kyūden 宮殿), appelées généralement gushiku, tel le château de Shuri. Bien que le caractère 城, shiro (château), soit utilisé pour écrire le mot gushiku, celui-ci diffère en particulier du château japonais par la présence dans son enceinte d'un espace sacré où résident les kami.

Pour ce qui est de la nature des kami vénérés dans les utaki (utaki no kami), elle est assez diverse. On y trouve, entre autres, des kami de la forge, des héros culturels et des « kami ancestraux » (sosen-gami 祖先神), autrement dit, les ancêtres fondateurs du village. Il arrive effectivement que des ossements humains soient découverts dans les utaki, mais il est très rare que les noms de ces personnages aient été conservés.

21 De manière générale, les utaki ne sont pas pourvus de bâtiments comparables aux bâtiments centraux (honden 本殿) ou aux oratoires (haiden 拝殿) des sanctuaires shintō (jinja 神社) du Japon. Un simple brûleur d'encens (kōro 香炉) ou une pierre marque le lieu où résident les kami. La présence de rochers ou de plantes tenus pour sacrés au centre de l'utaki laisse penser qu'il y a aussi une "composante animiste" (animizumuteki na yōso アニミズム的な要素) dans la religion d'Okinawa. Comme cela a été dit précédemment, les rites accomplis dans les utaki le sont par les femmes, et il est 
notable que les hommes ont très souvent interdiction d'y pénétrer. Cela contraste avec la situation au Japon où ce sont les femmes qui tendent à être exclues des lieux sacrés. En raison de leurs menstrues, elles y sont perçues comme des sources potentielles de pollution, et il leur est même parfois interdit de participer aux fêtes ou aux rites lorsqu'elles ont leurs règles. Dans la religion d'okinawa, au contraire, les femmes ne sont guère considérées comme porteuses de souillure, et les interdits concernant les règles assez peu contraignants pour les officiantes.

Examinons maintenant cet autre aspect de la religion d'Okinawa en rapport avec la notion de nirai-kanai (ニライ・カナイ). Ce mot désigne un monde différent (ikai 異界), un espace d'une autre nature, situé par-delà la mer ${ }^{12}$. Durant le septième mois du calendrier luni-solaire, dans quelques villages du nord de l'île d'okinawa, est organisée une fête appelée unjami (ウンジャミ) au cours de laquelle les kami du nirai-kanai sont supposés venir s'incarner dans les prêtresses pour être à la fois remerciés pour les bonnes récoltes de l'année écoulée et sollicités de renouveler celles-ci l'année suivante. La fête s'achève par un rite de renvoi des kami par-delà la mer.

On désigne sous le nom de « kami-visiteurs » (raihōshin 来訪神), par opposition aux kami qui résident dans les utaki, ceux des kami qui visitent ainsi le monde des humains à des moments déterminés de l'année. La région de Yaeyama offre un autre exemple de rite les mettant en scène. Appelé akamata-kuromata 赤い面・黒い面, « masque (ou visage) rouge / masque (ou visage) noir ", sa célébration coïncide avec la fête marquant la fin de la récolte du riz. À la différence des kami-visiteurs de l'unjami, qui prennent possession des prêtresses sans avoir eux-mêmes d'apparence concrète, ceux de l'akamata-kuromata sont matérialisés par des masques et par un déguisement végétal couvrant entièrement le corps des hommes qui les incarnent. Au cours de leur traversée du village, ils sont accueillis par les habitants de chaque maison, puis raccompagnés par eux sur le chemin à la fin de leur visite. La garde des masques et l'organisation du rite sont sous la responsabilité d'une sorte de société secrète masculine dirigée par les anciens du village. N'y sont admis que des adultes ayant subi une initiation sous la conduite de ces derniers, et il est strictement interdit à ses membres de divulguer le contenu du rite aux personnes extérieures, notamment aux femmes et aux enfants. Cela, bien sûr, rend extrêmement difficile, aux observateurs que nous sommes, de connaître le contenu du rite dans son entier. De plus, il est défendu de prendre des photos ou de faire des enregistrements sonores.

Il est intéressant de comparer ces deux rites dans lesquels des kami viennent d'un autre monde pour garantir l'abondance des récoltes. Dans le cas de l'unjami, où les rôles principaux sont tenus par des femmes, les kami prennent possession du corps même de celles-ci. Pour la circonstance, elles portent un vêtement particulier et se couvrent la tête de feuillages, mais leur visage reste découvert. Au contraire, dans le rite akamatakuromata, où les acteurs sont des hommes, ceux-ci ne doivent pas montrer leur visage aux spectateurs, et la présence des dieux est rendue tangible par l'emploi de masques et de déguisements. D'autres rites d'Okinawa mettent pareillement en scène des kamivisiteurs représentés par des masques et des déguisements, mais ce sont toujours des hommes qui en sont les acteurs. 


\section{Les rites à l'intention des ancêtres}

Cipango, 15 | 2008

Les rites à l'intention des ancêtres, appelés sosen saishi 祖先祭祀, sont un autre élément important de la culture populaire d'okinawa. Considérons d'abord ce qu'il en est au niveau domestique.

Pour les habitants d'Okinawa, la maison est l'unité responsable de la célébration des rites pour les ancêtres. On y trouve un «autel» (saidan 祭壇, butsudan 仏壇13) où résident leurs «âmes » (rei 霊), et devant lequel le maître ou la maîtresse de maison viennent fréquemment se recueillir et prier. Sur cet autel sont placés un brûleur d'encens et des «tablettes" (ihai 位牌) sur lesquelles sont inscrits les noms des ancêtres. Dans la cuisine de la maison, on honore également le «dieu du feu » (hi no kami 火の神), culte dont la maîtresse de maison a seule la charge ${ }^{14}$.

À Okinawa, comme au Japon, «l'héritage de la maison»(ie wo tsugu 家を継ぐ) ne désigne pas simplement la transmission des biens matériels, mais aussi, avec le butsudan, celle de la responsabilité des rites pour les ancêtres. C'est généralement l'aîné des garçons qui hérite de la maison. Dans le cas où il n'y a aucun enfant, la succession est assurée par le recrutement d'un « enfant adoptif » (yōshi 養子). Faute d'agir ainsi, la maison disparaîtrait avec la mort de ses occupants, et personne ne viendrait prendre soin d'eux sur l'autel des ancêtres, situation jugée peu enviable pour un défunt.

Sur ce point, il en va apparemment de même à Okinawa et au Japon. Il y a cependant une grande différence en ce qui concerne l'adoption. Au Japon, lorsque des parents n'ont d'autres enfants que des filles, c'est en général le couple que l'une d'elles forme avec son mari qui hérite de la maison. Dans ce cas, l'homme renonce à son « nom de famille » (sei 姓) pour prendre celui du père de son épouse. Mais cette solution n'est en principe pas envisageable de nos jours à Okinawa. Les filles quittent nécessairement leur maison en se mariant, et celui que l'on accueille comme fils adoptif doit normalement être « lié par le sang à la lignée paternelle » du chef de la maison (fukei no ketsuensha 父系の血縁者), le fils cadet d'un frère, par exemple. Ce choix témoigne de la force de l'idéologie patrilinéaire et des liens du sang dans l'organisation familiale à Okinawa. L'absence ou la faiblesse de cette idéologie dans certaines régions périphériques laisse toutefois penser qu'elle est d'apparition relativement récente.

Nous ne nous intéresserons ici qu'à un seul rite annuel (gyōji 行事) relatif au culte des ancêtres. Il s'agit du rite, ou fête, du bon 盆, qui a lieu durant le septième mois de l'ancien calendrier luni-solaire. Bon est un mot japonais, et à Okinawa ce rite est généralement appelé shichiguachi 七月, c'est-à-dire "septième mois ». Célébré dans toutes les régions du Japon, il est avec le nouvel an la fête la plus importante de l'année.

L'accueil des âmes des ancêtres, le treizième jour du septième mois, en marque le début ; il s'achève avec leur renvoi, le quinzième jour ${ }^{15}$. Le bon est précédé, le septième jour du septième mois, par la fête de tanabata 七夕, à l'occasion de laquelle les familles procèdent au nettoyage des tombes et annoncent aux ancêtres que la fête du bon approche. Durant la période du bon, la tradition veut que les gens visitent les maisons de leurs parents (shinseki 親戚), et qu'ils prient dans chacune d'elles devant l'autel dédié aux ancêtres.

31 Je dois attirer l'attention sur le fait que le rite du bon n'appartient pas véritablement à la culture indigène d'Okinawa. À Ikema 池間島, par exemple, comme dans d'autres îles du district de Miyako 宮古郡, sa célébration est aujourd'hui encore assez largement 
ignorée. C'est aussi le cas, plus au sud, dans les îles de Yaeyama. Les sources anciennes permettent d'affirmer que le rite du bon n'a en fait pénétré dans ces régions qu'à partir de la seconde moitié du XVIII ${ }^{e}$ siècle, notamment par l'entremise de fonctionnaires qui suivaient en cela des directives du gouvernement royal. Son adoption est une des conséquences de la mise en conformité de l'appareil étatique avec les principes du confucianisme chinois voulue alors par les dirigeants du royaume des Ryūkyū.

\section{Les munchū et le culte des ancêtres}

Il existe à Okinawa des "groupes de filiation» (shutsuji shūdan 出自集団) appelés munch̄ $\bar{u}$ 門中 ou parfois ichimun 一門. Ces groupes sont composés des descendants en ligne masculine d'un ancêtre fondateur (c'est ce que l'on appelle un "groupe de filiation patrilinéaire», fukei shutsuji shūdan 父系出自集団). Si les enfants appartiennent en règle au munchū de leur père, la situation des femmes mariées peut apparaître plus incertaine : sont-elles rattachées au munchū de leur maison natale ou à celui de la maison de leur mari? Bien que de nos jours prévale l'idée que l'épouse appartient au munchū de son mari, on observe qu'autrefois elle tendait à rester plus fortement liée à la lignée familiale de sa maison natale. Cela se manifestait, en particulier, par son rôle dans les activités rituelles, par sa contribution aux dépenses occasionnées par celles-ci, ainsi que par son inhumation dans la tombe de cette lignée. Cette proximité de la femme mariée avec sa maison natale est bien sûr à mettre en relation avec la croyance dans l'unai-gami examinée plus haut.

Le munchū se définit comme un groupement ayant pour fonction exclusive le culte des ancêtres (sosen saishi shūdan 祖先祭祀集団). Lors des cérémonies honorant les 《 ancêtres fondateurs » (shiso 始祖) et les « ancêtres lointains » (enso 遠祖, tôtsu-oya 遠 親), ses membres se rassemblent dans la «maison originaire», mūtuyā 元家, qui constitue le nucléus du munchū. Si les membres de ces groupements possèdent une tombe commune, appelée munchū- baka 門中墓, ce qui est surtout le cas dans la région sud de l'île d'Okinawa, ils s'y réunissent pour prier à l'occasion des fêtes rituelles du seimei (ou shimi 清明祭), au cours du troisième mois, et du jūrukunichi 十六日, le « seizième jour » du premier mois, jour de la première pleine lune de l'année (cette fête correspond au ko-shōgatsu 小正月japonais, le "petit Nouvel An » lunaire). Les munchū d'Okinawa diffèrent des groupes de filiation patrilinéaire qui existent dans de nombreuses sociétés, car ils n'ont d'autre fonction que d'organiser les cérémonies dédiées aux ancêtres proches ou lointains. Il est notable, en particulier, qu'ils ne possèdent pas de patrimoine foncier, hormis le terrain sur lequel est édifiée la tombe, et qu'ils ne constituent pas non plus des « unités exogamiques 》 (gaikon no tan.i 外婚の) 単位).

En réalité, le munchū est un élément relativement peu ancien de l'organisation sociale d'Okinawa, et il n'est d'ailleurs pas présent dans toutes les régions. C'est dans la partie sud de la région centrale de l'île d'okinawa, aux alentours de la capitale royale, qu'il est apparu et s'est d'abord propagé. S'il demeure complètement absent de certaines régions, il en est d'autres où son apparition est récente. D'origine chinoise ou coréenne, le munchū a été adopté par la classe des shizoku 士族 ${ }^{16}$ dans la seconde moitié du XVII ${ }^{\mathrm{e}}$ siècle, en même temps que le «système des rangs » (mibun seido 身分制度). En 1689, le gouvernement royal instaura un «bureau des généalogies»(keizu-za 系図座) pour recueillir les "généalogies» (kafu 家譜) dressées par les munchū. Avoir sa généalogie 
ainsi enregistrée attestait que l'on appartenait à la classe des shizoku. Ceux qui n'avaient en principe pas de généalogie à faire valoir, c'est-à-dire les «gens du commun » (heimin 平民), se virent dès lors désignés communément par le terme mukei 無系, les «sans généalogies ». Le munchū des shizoku s'est ensuite répandu en dehors de la région de Shuri et de Naha, à la fois par son adoption dans la paysannerie et par la réinstallation de familles aristocratiques en milieu rural à partir du XVIII ${ }^{e}$ siècle.

\section{À propos des tombes}

Ce qui frappe d'abord, au sujet des tombes d'okinawa, c'est la grande taille de beaucoup d'entre elles ${ }^{17}$. Il y a au moins deux raisons à cela. La première est que dans la région voisine de la capitale, où il est fréquent, comme cela a été dit, que les tombes soient la propriété commune de munchā, il est nécessaire que leur taille soit en rapport avec le nombre important de membres que comptent ces groupements familiaux. L'autre raison concerne plus précisément le traitement du corps du défunt. Avant l'introduction de la crémation à Okinawa, qui ne date que de l'après-guerre, le cadavre était placé dans un cercueil que l'on introduisait en entier dans la chambre tombale. Au terme d'une période déterminée, généralement de trois ans, les restes du défunt étaient sortis dans la petite " cour-jardin », nā (niwa 庭 en japonais), aménagée sur le devant de la plupart des tombes, pour y procéder au «nettoyage des os » (shinkuchi, senkotsu 洗 骨) ${ }^{18}$. Il était donc nécessaire de prévoir un large espace à l'intérieur de la tombe permettant, d'une part, d'y entreposer temporairement plusieurs cercueils, d'autre part, d'y conserver la grande quantité d'ossements résultant de ce traitement des cadavres.

Lors des visites aux tombes, en particulier à l'occasion des fêtes de jūrukunichi, seimei et tanabata, après avoir adressé des prières aux morts récents et aux ancêtres, les familles s'installent dans la petite « cour-jardin », nā, et y ouvrent des « boîtes à repas » (jūbako 重箱). Ce repas festif, fait de poisson et de sake, est vécu comme un échange avec les défunts dont les mémoires conservent le souvenir, comme aussi, plus vaguement, avec l'ensemble des ancêtres.

Comme les munchū, toutefois, ce genre de réunion familiale semble n'être pas d'une très grande ancienneté. Les tombes que nous connaissons aujourd'hui, et avec elles, sans doute, les rites qui s'y rattachent, n'ont en effet été introduites à Okinawa qu'au XvII siècle $^{19}$. Un texte de 1766 relatif à l'île de Minna 水納島, près de Miyako, nous apprend, par exemple, qu'il n'y avait jusque-là aucune tombe sur cette île. On se contentait simplement d'y enterrer les cadavres (maisō 埋葬) ici ou là, mais ces emplacements n'étaient le lieu d'aucune cérémonie. Des habitants édifièrent alors une "tombe collective » (kyōōo-baka 共同墓, muyai-baka 模合墓) dans laquelle ils rassemblèrent les ossements des cadavres dispersés à travers l'île. C'est aussi à partir de ce moment-là que des cérémonies commencèrent à être organisées devant la tombe.

Cette transformation des pratiques funéraires va de pair avec l'adoption du bon, des tablettes funéraires et plus généralement du culte des ancêtres dans sa forme actuelle, dont il a été précédemment question. Bien que la façon dont ces changements se sont ensuite propagés aux autres régions de l'archipel soit objet de conjectures, tous sont d'abord apparus dans la classe des shizoku de la région de Shuri, en même temps que le confucianisme chinois devenait l'idéologie officielle du gouvernement royal. En conclusion de cette rapide présentation, je voudrais insister sur la nécessité de ne pas 
négliger l'influence des élites et des politiques d'État, comme le montre l'exemple d'Okinawa, pour comprendre l'évolution des cultures populaires.

\section{ANNEXES}

Présentation de l'auteur

Akamine Masanobu 赤嶺政信 est professeur d'études folkloriques (minzokugaku 民俗

学) dans le département de droit et de lettres de l'université nationale des Ryūkyū 琉球 大学法文学部球大学法文学部 à Nishihara 西原市, Okinawa. Né en 1954 à Haebaru 南 風原, au sud de Shuri, il commence des études d'ethnologie à l'université des Ryūkyū, d'où il sort diplômé en 1978. Il poursuit sa formation à l'université de Tsukuba sous la direction, notamment, du professeur Miyata Noboru 宮田登. C'est aujourd'hui l'un des meilleurs connaisseurs de la culture populaire des îles Ryūkyū. Ses enquêtes de terrain portent sur toute l'étendue de cet archipel, y compris sur les îles rattachées au département de Kagoshima. Il a également mené des recherches comparatives dans le sud-est de la Chine. C'est toutefois l'île de Kudaka 久高島, point d'ancrage essentiel dans la symbolique spatiale sur laquelle reposait, idéologiquement et rituellement, l'autorité de l'ancienne monarchie des Ryūkyū, qui est l'objet de ses recherches les plus suivies. Ses travaux ont été récompensés en 1996 par le prix Higa Shunchō décerné par l'Association pour la culture d'Okinawa (Okinawa bunka kyōkai 沖縄文化協会). En 2004, il a également reçu de l'Association d'Okinawa (Okinawa kyōkai 沖縄劦会) un prix encourageant les recherches sur cette région (Okinawa kenkyū shōrei shō 沖縄研究将励 賞). Il est l'auteur de très nombreuses publications scientifiques et de vulgarisation, parmi lesquelles :

«Sonraku no shiso to munchū no shiso : Kudaka-jima no munchū-ka genshō no ichisokumen»村落の始祖と門中の始祖 : 久高島の門中化現象の一側面, Okinawa minzoku kenkyū 沖縄民俗研究, 23, 2005, p. 97-116.

«Jiwari gumi-Mabutchi gumi-Yadui. Kudaka-jima sonraku saishi soshiki ni tsuite no hoi »地割組・マブッチ組・ヤドゥイ : 久高島村落祭䃼組織についての補遺, Ryūkyu daigaku hōbungakubu ningenkagaku kakiyō琉球大学法文学部人間科学科紀要, vol. 14, 2004, p. 169-182.

«Ōken ni manazasareta shima : Okinawa-Kudakajima »王権にまなざされた島 : 沖縄一 久高島, in Kenryoku 権力 (Gendai minzokushi no chihei 2 現代民俗誌の地平 2), sous la dir. de Akasaka Norio 赤坂憲雄, Asakura shoten 朝倉書店, 2004, p. 181-206.

《Amami, Okinawa no sōsō bunka : sono dentō to hen.yō »奄美・沖縄の葬送文化：そ の层統と変容, in Sōgi to haka no genzai : minzoku no henyō葬儀と墓の現在 : 民俗の变 容, sous la dir. de Kokuritsu rekishi minzoku hakubutsukan 国立歴史民俗博物館, Yoshikawa kōbunkan 吉川弘文館, 2002, p. 3-27. 
《Ie no fōkuroa : Okinawa, Miyako no baai »家のフォークロア : 沖縄・宮古の場合, in Shin.i to shinkō no minzoku 心意と信仰の民俗, Yoshikawa kōbunkan 吉川弘文館, 2001, p. 266-294.

«Rekishi no naka no Okinawa : Isaihō saikō» 榞史のなかの沖縄 : イザイホー再考, in Minzoku no shisō 民俗の思想, sous la dir. de Miyata Noboru 宮田登, Asakura shoten 朝 倉書店, 1998, p. 203-216.

Shima no miru yume. Okinawa minzokugaku sanpo シマの見る夢.おきなお民俗学散步, Naha 那覇, Bōdāinku ボーダーインク, 1998, 208 p.

« Noro to yuta »ノロとユタ, in Kōza Nihon no minzokugaku 7 : kami to reikon no minzoku 講座日本の民俗学 7 : 神と霊魂の民俗, sous la dir. de Akata Mitsuo 赤田光男 et Komatsu Kazuhiko 小松和彦, Yūsankaku shuppansha 雄山閣出版社, 1997, p. 147-160.

《Okinawa ni okeru sosen saishi no seiritsu » 沖縄における祖先祭祀の成立, Shūkyō kenkyū 宗教研究, 71-1, 1997, p. 55-78.

«Okinawa no sorei shinkō : sosen wa kami ni naru ka » 沖縄の祖霊信仰 : 祖先は神に なるか, in Reikon wo meguru Nihon no shinso 霊魂をめぐる日本の深層, sous la dir. de Umehara Takeshi 梅原猛 et Nakanishi Susumu 中西進, Kadokawa sensho 角川選書 271, 1996, p. 71-95.

"Yaeyama shotō no kenchiku girei : naka-bashira shinkō to yuipitu ganashi wo megutte»八重山諸島の建築儀礼：中柱信仰とユイピトゥガナシをめぐって, Okinawa bunka 沖縄文化, 27-2, 1992, p. 6-35.

《Okinawa no sorei shinkō : sono jakkan no mondai-ten » 沖縄の祖霊信仰 : その若干 の問題点, Okinawa bunka kenkyū 沖縄文化研究, 17, 1991.

« Kudaka-jima no shūkyō seikatsu ni okeru sorei (shirei) kannen» 久高島の宗教生活 における祖霊 (死霊) 観念, in Kami, mura, hito : Ryūkyū-ko ronso 神・村. 人：琉球弧 論叢, Daiichi shobō 第一書房, 1991, p. 343-372.

«Okinawa Kudaka-jima no "munchū" sei : Kudaka-jima sonraku saishi soshiki rikai no tame no yobiteki kōsatsu » 沖縄久高島の「門中制」：久高島村落祭祀組織理解のた め予備的考察, Minzokugaku kenkyū 民族学研究, 47-4, 1983, p. 336-355.

\section{NOTES}

1. Les documents officiels le désignent par l'expression "gouvernement royal de Chūzan du pays de Ryūkyū » (Ryūkyū-koku Chūzan-ōfu 琉球国中山王府), Chūzan étant le nom du petit royaume qui unifia militairement et politiquement l'île d'Okinawa. [NDT.]

2. Satsuma interdit au royaume tout contact avec des pays étrangers à l'exception de l'Empire chinois, avec lequel il put poursuivre ses relations diplomatiques et commerciales. L'influence culturelle chinoise s'est même accentuée aux XVII et XVIII ${ }^{e e}$ siècles, comme cela est évoqué plus loin. [NDT.]

3. Ce titre est parfois lu Shirutuyā bushi ou Shiratui bushi. [NDT.]

4. La transcription-traduction en japonais standard, donnée entre crochets, de cette strophe et de la suivante est empruntée à Iha Fuyū 伊波普猷, Onari-gami no shima をなり神の島, vol. 1, Tōyō bunko 東洋文庫 227, Heibonsha, 1973, p. 5-6. Pour la lecture du texte original, cet auteur s'en tient presque entièrement à la phonétique japonaise. Bien que le sujet fasse débat, en voici la version la plus commune dans le dialecte de Shuri-Naha : uni (ou peut-être one dans le langage de 
la cour) nu takatumu ni / shiratuya ga ichon/shiratuya ya aran / uminai ushiji (voir, par exemple, l'article de Higa Etsuko 比嘉悦子 《Shiratori (Shirutuyā) bushi » 白鳥節 dans Okinawa daihyakka jiten 沖縄大百科事典, vol. 2, Okinawa Taimusu-sha 沖縄夕イムス社, 1983, p. 458). Les mots de la dernière ligne, unai no shiji, désignent le " pouvoir spirituel (protecteur) de la sœur ». Iha Fuyū choisit de les rendre en japonais par l'expression shimai no iki-mitama 姉妹の生御魂, « esprit vivant - ou âme vivante - de la sœur ». La transcription unai no reiryoku ウナイ (思姉)の霊力, " pouvoir spirituel de la sœur », est cependant plus courante, unai étant, comme nous l'avons vu plus haut, un terme d'usage spécifiquement masculin par lequel les hommes désignent leurs sœurs. Le terme shiji, sans correspondant en japonais, désigne le pouvoir des kami en général. [NDT.]

5. Uminai ga tīsaji/maboru (ou maburu) kandaimono (ou munu)/hiki (ou fichi) mawachi tabore / Yamatu madin, ce qui peut se traduire ainsi : la pièce d'étoffe tissée par la sœur [tīsāji 手 巾, rendu en japonais par tenugui 手拭い, « serviette»] est pour nous comme un dieu protecteur ; sous son égide nous irons jusqu'au Japon. [NDT.]

6. Beaucoup de témoignages rappellent que l'éducation reçue par les enfants dans leur famille, au moins jusqu'au milieu du siècle dernier, insistait sur le respect dû par les garçons à leurs sœurs, et, pour ces dernières, sur la nécessité de veiller sur leurs frères. Le manque d'égards envers une sœur, disait-on, pouvait causer le courroux de son esprit, même à son insu. [NDT.]

7. À Okinawa, les tombes sont collectives et la propriété de lignées familiales, $c f$. infra.

8. Pour Mabuchi Tōichi 馬淵東一, le pouvoir de protection de la sœur dans les îles Ryūkyū serait à rapprocher de celui manifesté, de manière plus codifiée, dans les sociétés à faible patrilinéarité qu'il désigne comme étant de type "océanien », par opposition au type « indonésien » ("Shimai no reiteki yūetsu 姉妹の霊的優越》, in Mabuchi Tōichi chosakushū 馬淵東一著作集, vol. 3, Shakai shisō sha 社会思想社, 1974, p. 163-191). [NDT.]

9. La volonté des dirigeants du royaume de se conformer à l'orthodoxie confucéenne, concrétisée par les mesures prises en 1667 et 1673 par le régent Shō Jōken 向象賢 (ou Haneji Chōshū 羽地朝 秀), entraîna, d'une part, la rétrogradation de la kikoe-ōgimi à un rang inférieur à celui de l'épouse du roi, d'autre part, l'arrêt de la participation de ce dernier aux cérémonies où il apparaissait subordonné à la prêtresse royale. [NDT.]

10. Pour autant, l'attribution de ces charges répondait aussi à des critères successoraux assez divers. [NDT.]

11. Des enquêtes récentes ont montré le caractère très lucratif des activités des yuta. Par les réagencements des restes des défunts, entre autres conseils prodigués à leurs clients pour remédier à leurs maux, elles se sont révélées être des agents efficaces de la diffusion de l'idéologie patrilinéaire dont il sera question plus loin. [NDT.]

12. Situé dans ou sur la mer, ce lieu est généralement identifié avec la ligne d'horizon. [NDT.]

13. Appelé aussi kamidana 神棚 dans le sous-archipel de Miyako 宮古群島. [NDT.]

14. Le dieu du feu est traditionnellement représenté par trois pierres. [NDT.]

15. Autrefois, le renvoi des âmes des ancêtres avait souvent lieu le seizième jour.

16. Ou samurēe en langue d'Okinawa. Cette aristocratie était principalement constituée par les descendants des seigneurs provinciaux contraints d'abandonner leurs armes et de résider près du château de Shuri sous le règne du roi Shō Shin 尚真 (1477-1526).

17. Ces tombes, dont on trouve le modèle dans la province chinoise du Fujian, ont un toit en forme de carapace de tortue qui leur vaut le nom de kāminakū-baka, kamekō-baka 龟甲墓. [NDT.] 18. Le nettoyage était effectué par les plus proches parents du défunt. Les os, lavés avec de l'eau et du sake, étaient placés dans une urne funéraire rangée ensuite dans la tombe [NDT.]. Cette coutume était peu répandue dans l'île de Miyako [Note de l'auteur].

19. La première tombe du type kamekō-baka fut construite à Shuri vers 1685. [NDT.] 


\section{RÉSUMÉS}

Annexé par le Japon en 1879, occupé par les américains entre 1945 et 1972, Okinawa présente de nombreuses originalités ainsi qu'une histoire et une culture propres.

Annexed by Japan in 1879, occupied by the U.S. Army between 1945 and 1972, Okinawa has many distinctive features and a unique history and culture.

\section{INDEX}

Mots-clés : culture populaire, études folkloriques, filiation, folklore, Iha Fuyū 伊波普猷 (1876-1947), morts - culte, parenté - système de キーワード : taishū bunka 大衆文化, minzokugaku 民俗学, shutsuji 出自, kakei 家系, minzoku 民俗, Iha Fuyū 伊波普猷 (1876-1947), sosen sūhai 祖先崇捃, Okinawa 沖縄, Ryūkyū 琉球, jinruigaku 人類学, minzokugaku 民族学

Keywords : Ancestor Worship, Anthropology, Death Ritual, Ethnology, Folklore, kinship, Okinawa, Paternity, Popular Culture

Thèmes : anthropologie, ethnologie

Index géographique : Okinawa, Ryūkyū 